\title{
Prevalence of anti-malarial resistance genes in Dakar, Senegal from 2013 to 2014
}

\author{
Agathe Boussaroque ${ }^{1}$, Bécaye Fall², Marylin Madamet ${ }^{3,4,5}$, Khalifa Ababacar Wade ${ }^{6}$, Mansour Fall? \\ Aminata Nakoulima ${ }^{8}$, Khadidiatou Ba Fall ${ }^{9}$, Pierre Dionne ${ }^{10}$, Nicolas Benoit ${ }^{3,4,5}$, Bakary Diatta ${ }^{7,11}$, Yaya Diemé2 \\ Boubacar Wade ${ }^{11}$ and Bruno Pradines ${ }^{1,2,4,5^{*}}$
}

\begin{abstract}
Background: To determine the impact of the introduction of artemisinin-based combination therapy (ACT) on parasite susceptibility, a molecular surveillance for antimalarial drug resistance was conducted on local isolates from the Hôpital Principal de Dakar between November 2013 and January 2014 and between August 2014 and December 2014.

Methods: The prevalence of genetic polymorphisms in antimalarial resistance genes (pfcrt, pfmdr1, pfdhfr and pfdhps) was evaluated in 103 isolates.

Results: The chloroquine-resistant haplotypes CVIET and CVMET were identified in 31.4 and $3.9 \%$ of the isolates, respectively. The frequency of the pfcrt K76T mutation was increased from $29.3 \%$ in 2013-2014 to $43.2 \%$ in 2014. The pfmdr1 N86Y and Y184F mutations were identified in 6.1 and $53.5 \%$ of the isolates, respectively. The pfdhfr triple mutant (S108N, N51I and C59R) was detected in the majority of the isolates ( $82.3 \%)$. The prevalence of quadruple mutants (pfdhfr S108N, N511, C59R and pfdhps A437G) was 40.4\%. One isolate (1.1\%) harboured the pfdhps mutations A437G and K540E and the pfdhfr mutations S108N, N51I and C59R.

Conclusions: Despite a decline in the prevalence of chloroquine resistance due to the official withdrawal of the drug and to the introduction of ACT, the spread of resistance to chloroquine has continued. Furthermore, susceptibility to amodiaquine may be decreased as a result of cross-resistance. The frequency of the pfmdr1 mutation N86Y declined while the Y184F mutation increased in prevalence, suggesting that selective pressure is acting on $p f m d r 1$, leading to a high prevalence of mutations in these isolates and the lack of specific mutations. The $50.5 \%$ prevalence of the pfmdr 1 polymorphisms N86Y and Y184F suggests a decrease in lumefantrine susceptibility. Based on these results, intensive surveillance of ACT partner drugs must be conducted regularly in Senegal.
\end{abstract}

Keywords: Malaria, Plasmodium falciparum, Anti-malarial, In vitro, Resistance, Senegal, Molecular marker

\section{Background}

Due to increasing chloroquine resistance, the first-line malaria treatment in Senegal was switched to sulfadoxine-pyrimethamine with amodiaquine in 2004. In 2006, the Senegalese National Malaria Control Programme recommended artemisinin-based combination therapy $(\mathrm{ACT})$ as the first-line treatment for uncomplicated

\footnotetext{
*Correspondence: bruno.pradines@free.fr

1 Unité de Parasitologie et d'Entomologie, Département des Maladies Infectieuses, Institut de Recherche Biomédicale des Armées, Brétigny Sur Orge, France

Full list of author information is available at the end of the article
}

malaria. Therefore, the first-line therapy for uncomplicated malaria became artemether-lumefantrine or artesunate-amodiaquine. The dihydroartemisininpiperaquine combination was then recommended as a second-line treatment for uncomplicated Plasmodium falciparum malaria in Senegal.

Intermittent preventive treatment (IPT) consists of administering sulfadoxine-pyrimethamine and one dose of artesunate during the transmission season and resulted in a $90 \%$ reduction in incidence of clinical malaria in Senegal [1]. Administered once a month to all children 
or pregnant women, this seasonal IPT can provide a high degree of protection against malaria.

The combination of sulfadoxine-pyrimethamine and amodiaquine was more effective than sulfadoxinepyrimethamine and artesunate or amodiaquine and artesunate in malaria preventive treatment [2]. During IPT with sulfadoxine-pyrimethamine and piperaquine, only $3.4 \%$ of the treated children had malaria [3].

Since the introduction of ACT and IPT trials in Senegal, very few studies have examined $P$. falciparum resistance to antimalarial drugs. To determine the impact of the introduction of new anti-malarial drugs on parasite susceptibility, a molecular study of anti-malarial drug resistance was conducted on local isolates from the Hôpital Principal de Dakar between November 2013 and January 2014 and between August 2014 and December 2014. The prevalence of genetic polymorphisms in antimalarial resistance genes, such as the $P$. falciparum chloroquine resistance transporter ( $p f c r t$ ) for chloroquine [4], $P$. falciparum multidrug resistance 1 (pfmdr1), which is involved in mefloquine resistance [5] and potentially in quinoline resistance [6, 7], P. falciparum dihydrofolate reductase (pfdhfr) for pyrimethamine [8] and P. falciparum dihydropteroate synthase (pfdhps) for sulfadoxine, were evaluated [9].

\section{Methods}

\section{Plasmodium falciparum isolates}

In total, 103 symptomatic patients were recruited at the Hôpital Principal de Dakar. Fifty-nine P. falciparum isolates were collected between November 2013 and January 2014 and 44 between August 2014 and December 2014. The majority of patients $(64 \%)$ were recruited from the emergency department. The other patients were recruited from the intensive care unit (12\%), paediatric department (7\%), infectious diseases department (5\%), maternity department (3\%), and other units (9\%). Antimalarial treatment prior to admission was not recorded. Despite the WHO's recommendations, the $P$. falciparum treatment administered at the Hôpital Principal de Dakar until November 2014 was quinine followed by artesunate or artemether-lumefantrine. All the patients or their parents/guardians provided their verbal consent before blood collection. The ethical committee of the Hôpital Principal de Dakar approved the study.

Peripheral venous blood samples were collected in Vacutainer ${ }^{\circledR}$ ACD tubes (Becton-Dickinson, Rutherford, NJ, USA) prior to patient treatment. The diagnosis was performed on thin blood smears stained using a RAL ${ }^{\circledR}$ kit (Réactifs RAL, Paris, France) to determine $P$. falciparum density and to confirm species-specific monoinfection. The level of parasitaemia ranged from 0.001 to $3.3 \%$ in 2013-2014 and 0.06 to $14.1 \%$ in 2014.

\section{Nucleic acid extraction}

Total genomic DNA was extracted from blood sample using a QIAamp DNA Blood Mini Kit according to the manufacturer's recommendations (Qiagen, Germany).

\section{Anti-malarial resistance gene single-nucleotide polymorphisms (SNPs)}

Four genes, $p f c r t, p f m d r 1, p f d h f r$ and $p f d h p s$, were amplified by PCR using the reaction conditions described in Table 1 [10-12]. The reaction mixture included $2.5 \mu \mathrm{L}$ of genomic DNA, 1X reaction buffer (Eurogentec), $200 \mu \mathrm{M}$ of deoxynucleoside triphosphate mixture (dGTP, dATP, dTTP and dCTP) (Euromedex, Souffelweyersheim, France), variable concentration of $\mathrm{MgCl}_{2}$ (Table 1), $0.32 \mu \mathrm{M}$ of forward and reverse primers and one unit of Red Diamond Taq ${ }^{\circledR}$ DNA polymerase (Eurogentec) in a final volume of $25 \mu \mathrm{L}$. The thermal cycler (T3 Biometra, Archamps, France) was programmed as follows: an initial denaturation at $94{ }^{\circ} \mathrm{C}$ for $5 \mathrm{~min}$ followed by 40 cycles of $94{ }^{\circ} \mathrm{C}$ for $30 \mathrm{~s}$, specific hybridization temperature for variable elongation times (Table 1 ) and $72{ }^{\circ} \mathrm{C}$ for extension at $1 \mathrm{~min}$ per $1000 \mathrm{bp}$, and a final 5 min extension step at $72{ }^{\circ} \mathrm{C}$. Purified genomic DNA from $P$. falciparum clone 3D7 was used as a positive control, and water and human DNA were used as negative controls. The reaction products were sequenced using the BigDye Terminator v3.1 Cycle Sequencing Kit (Applied Biosystems) with the primers described in Table 1 . The sequencing reaction products were purified using the BigDye XTerminator ${ }^{\circledR}$ Purification Kit (Applied Biosystems) in accordance with the manufacturer's instructions. Sanger sequencing of PCR products was performed using an ABI Prism 3100 analyser (Applied Biosystems). The sequence data were analysed using Vector NTI Advance ${ }^{\mathrm{TM}}$ software (version 11, Invitrogen, Cergy Pontoise, France).

\section{Results}

Of 103 P. falciparum isolates collected at the Hôpital Principal de Dakar, 59 isolates were obtained between November 2013 and January 2014 and 44 between August 2014 and December 2014.

The $p f c r t$ gene was successfully sequenced in 102 samples. The frequency of the haplotype CVIET was $31.4 \%$ ( $\mathrm{n}=32$ isolates), the haplotype CVMET was $3.9 \%(\mathrm{n}=4$ isolates) and the haplotype CVMNK was $64.7 \%(\mathrm{n}=66$ isolates). A molecular resistance profile was identified in $35.3 \%$ of cases $(n=36$ isolates), including $29.3 \%(n=17$ isolates) in 2013-2014 and $43.2 \%(\mathrm{n}=19$ isolates $)$ in 2014. The difference is not significant ( $\mathrm{P}$ value $=0.146$, Pearson's Chi squared test). The CVEMT haplotype was first identified in the 2014 malaria season.

The results for $p f m d r 1$ polymorphisms are shown in Table 2. The frequency of the $86 \mathrm{Y}$ mutation was $5.1 \%$ 
Table 1 PCR for anti-malarial resistance genes

\begin{tabular}{|c|c|c|c|c|c|}
\hline Gene & Primers & Amplicon (pb) & {$\left[\mathrm{MgCl}_{2}\right](\mathrm{mM})$} & $\operatorname{Tm}\left({ }^{\circ} \mathrm{C}\right)$ & Elongation time (s) \\
\hline \multirow[t]{4}{*}{ pfert } & Forward CRT76-F & 182 & 4.5 & 55 & 20 \\
\hline & TTG GTA AAT GTG CTC ATG TG T & & & & \\
\hline & Reverse CRT76-R & & & & \\
\hline & ACA AAT AAA GTT GTG AGT TTC GGA TG & & & & \\
\hline \multirow[t]{4}{*}{ pfmdr1-1 } & Forward MDR1-1F & 610 & 2.5 & 52 & 30 \\
\hline & AGA GAA AAA AGA TGG TAA CCT CAG & & & & \\
\hline & Reverse MDR1-1R & & & & \\
\hline & ACC ACA AAC ATA AAT TAA CGG & & & & \\
\hline \multirow[t]{4}{*}{ pfmdr1-2 } & Forward MDR1-2F & 890 & 2.5 & 56 & 60 \\
\hline & CAG GAA GCA TTT TAT AAT ATG CAT & & & & \\
\hline & Reverse MDR1-2R & & & & \\
\hline & CGT TTA ACA TCT TCC AAT GTT GCA & & & & \\
\hline \multirow[t]{4}{*}{ pfdhfr } & Forward Dhfr-F & 562 & 2.5 & 52 & 20 \\
\hline & ACG TTTTCG ATA TTT ATG C & & & & \\
\hline & Reverse Dhfr-R & & & & \\
\hline & TCA CATTCA TAT GTA CTA TTT ATT C & & & & \\
\hline \multirow[t]{4}{*}{ pfdhps } & Forward Dhps-F & 971 & 2.5 & 53 & 20 \\
\hline & TTTTGT TGA ACC TAA ACG TG & & & & \\
\hline & Reverse Dhps-R & & & & \\
\hline & AAA CGT CAT GAA CTC TTA TTA GAT & & & & \\
\hline
\end{tabular}

Table 2 Frequency (\%) and number (no) of the pfmdr1 mutations

\begin{tabular}{lrlcl}
\hline Codon & No & $\begin{array}{l}\text { Wild type \% } \\
\text { (no) }\end{array}$ & Mutated \% (no) & $\begin{array}{l}\text { Wild type/ } \\
\text { mutated \% (no) }\end{array}$ \\
\hline N86Y & 99 & $93.9(93)$ & $5.1(5)$ & $1(1.0)$ \\
Y184F & 99 & $46.5(46)$ & $53.5(53)$ & $0(0)$ \\
S1034C & 102 & $100(102)$ & $0(0)$ & $0(0)$ \\
N1042D & 102 & $100(102)$ & $0(0)$ & $0(0)$ \\
\hline
\end{tabular}

( $\mathrm{n}=5$ isolates), and one mixed sample $(1 \%)$ harboured both $\mathrm{N} 86$ and $86 \mathrm{Y}$ alleles. The 184F mutation frequency was $53.5 \%$ ( $\mathrm{n}=53$ isolates), and five of the six isolates harboured both the $86 \mathrm{Y}$ and $184 \mathrm{~F}$ codons. Parasites with the N86 allele and the 184F mutation represented $50.5 \%$ of the isolates. No new SNPs were detected in the pfmdr1 gene.

The results for $p f d h f r$ polymorphisms are presented in Table 3. The mutation frequencies were $87.9 \%$ for the S108N mutation and $85.9 \%$ for both the N51I and C59R polymorphisms. The triple mutant (S108N, N51I and C59R) was detected in $82.3 \%$ of samples.

The results for the pfdhps polymorphisms are presented in Table 4. The isolates harboured A437G in $47.2 \%$ of the cases, $\mathrm{S} 436 \mathrm{~A}$ in $20.2 \%$ of the cases, A613S in $3.2 \%$ of the cases, $\mathrm{K} 540 \mathrm{E}$ in $2.1 \%$ of the cases and A581G in $1.1 \%$ of the cases.
Table 3 Frequency (\%) and number (no) of the pfdhfr mutations

\begin{tabular}{|c|c|c|c|}
\hline Codon & No & Wild type \% (no) & Mutated \% (no) \\
\hline S108N & 99 & $12.1(12)$ & $87.9(87)$ \\
\hline N51। & 99 & $14.1(14)$ & $85.9(85)$ \\
\hline C59R & 99 & $14.1(14)$ & $85.9(85)$ \\
\hline I164L & 99 & $100(99)$ & $0(0)$ \\
\hline
\end{tabular}

The prevalence of the quadruple mutant (pfdhfr $108 \mathrm{~N}$, 51I, 59R and pfdhps 437G) was $40.4 \%$. One isolate (1.1\%) simultaneously harboured the two pfdhps mutations $437 \mathrm{G}$ and $540 \mathrm{E}$ and the three $p f d h f r$ mutations $108 \mathrm{~N}, 51 \mathrm{I}$ and 59R.

\section{Discussion}

In total, isolates from only 103 malaria patients were collected in 2013 and 2014 at the Hôpital Principal de Dakar, 55 during the 2013-2014 malaria season and 44 during the 2014-2015 season. This is due to the decreased prevalence of malaria in Senegal (reduction of $27.6 \%$ from 2013 to 2014) [13]. Chloroquine resistance is principally mediated by $p f c r t$ mutations in different parts of the world [14]. In this study, the pfcrt gene was mutated in $35.3 \%$ of the patients recruited at the Hôpital Principal de Dakar in 2013 and 2014, including $29.3 \%$ of the 
Table 4 Frequency (\%) and number (no) of the pfdhps mutations

\begin{tabular}{llll}
\hline Codon & No & Wild type \% (no) & Mutated \% (no) \\
\hline S436A & 89 & $79.8(71)$ & $20.2(18)$ \\
A437G & 89 & $52.8(47)$ & $47.2(42)$ \\
K540E & 94 & $14.1(97.9)$ & $2.1(2)$ \\
A581G & 94 & $98.9(93)$ & $1.1(1)$ \\
A613S & 94 & $96.8(91)$ & $3.2(3)$ \\
\hline
\end{tabular}

cases in the 2013-2014 season and $43.2 \%$ of the cases in the 2014-2015 season. This increase in chloroquine resistance has been observed in recent years following a decrease due to the withdrawal of chloroquine and the introduction of ACT in 2002 in Senegal (Table 5). Before the introduction of ACT in Senegal, the prevalence of isolates harbouring the pfcrt $\mathrm{K} 76 \mathrm{~T}$ and in vitro chloroquine resistance was above 50 and $40 \%$, respectively, in Dakar and its suburb Pikine and in south areas (Dielmo and Ndiop) [15-21]. During the beginning of the ACT implementation (2004-2009), the prevalence of K76T mutant parasites maintained around $50 \%$ [19, 22]. From 2009 to 2011, the prevalence of K76T mutant parasites and in vitro chloroquine resistance decreased to 40 and $25 \%$, respectively in Dakar [23-25]. Since 2013, the level of chloroquine resistance has increased again to that of 2002 in Dakar [26, 27].

While chloroquine is no longer used in Senegal, the prevalence of in vitro chloroquine resistance and of the pfcrt K76T mutation has increased. Two hypotheses could explain the observed increase: (i) the use of artesunate-amodiaquine in Senegal led to the emergence of resistant parasites to amodiaquine; (ii) the development of cross-resistance to chloroquine and monodesethylamodiaquine increased the resistance [23, 28]. This study describes the first detection of the CVMET haplotype in Senegal. In Senegal, the 76T mutation has previously been associated with the CVIET haplotype.

The isolates harbouring the pfmdr1 mutations 86Y, $184 \mathrm{~F}, 1034 \mathrm{C}$ and 1042D were identified in 6.1, 53.5, 0 and $0 \%$ of the patients, respectively. The prevalence of $86 \mathrm{Y}$ has decreased over the past few years in Senegal from $>30 \%$ in 2000 to $6 \%$ in 2013-2014 (Table 6) [18-20, 22, $24,25]$. Since 2010, the prevalence of parasites harbouring the $184 \mathrm{~F}$ mutation has remained stable and above $50 \%$ in Dakar $[24,25]$. This prevalence has more than doubled from $30 \%$ in 2008 to greater than $70 \%$ in 2011 in Thiès [22]. The frequency of the pfmdr1 mutation N86Y declined, while the frequency of the Y184F mutation increased, suggesting that selective pressure is acting on $p f m d r 1$, leading to a high prevalence in these isolates and the lack of specific mutations. The role of polymorphisms in $p f m d r 1$ is still debated. The $86 \mathrm{Y}$ mutation was associated with increased in vitro susceptibility of $P$. falciparum parasites to dihydroartemisinin, lumefantrine, monodesethylamodiaquine and mefloquine [29]. In contrast, this pfmdr1 86Y mutation was associated with a decrease of in vitro susceptibility to dihydroartemisinin, lumefantrine, and mefloquine in P. falciparum isolates from Asia [30], Kenya [31] and Benin [32]. Field studies in east Africa have also shown selection of the N86 allele

Table 5 Molecular (pfcrt K76T) and in vitro studies on evaluation of $P$. falciparum susceptibility to chloroquine in Senegal

\begin{tabular}{|c|c|c|c|c|}
\hline Year of collection & Site of collection & In vitro chloroquine resistance (\%) & pfcrt 76T & References \\
\hline 1996 & Dielmo/Ndiop & 49 & & [15] \\
\hline 1997-1998 & Dielmo/Ndiop & 43.5 & & [16] \\
\hline 1999 & Dielmo/Ndiop & 55 & & [17] \\
\hline 2000 & Pikine & 31 & $79 \%$ & [18] \\
\hline 2000-2003 & Pikine & & $72.4 \%$ & [19] \\
\hline 2001 & Pikine & & $64 \%$ & [20] \\
\hline 2002 & Dakar & 52 & $54 \%$ & [21] \\
\hline 2004-2005 & Pikine & & $47.2 \%$ & [19] \\
\hline $2006-2009$ & Pikine & & $59.5 \%$ & [19] \\
\hline $2008-2011$ & Thies & & $>50 \%$ & [22] \\
\hline 2009-2010 & Dakar & 22 & & [23] \\
\hline 2009-2010 & Dakar & & 37.2 & [24] \\
\hline 2010-2011 & Dakar & 24.2 & $43.6 \%$ & [25] \\
\hline 2013-2014 & Dakar & 50 & & {$[26]$} \\
\hline 2013-2014 & Dakar & & 29.3 & Present data \\
\hline 2014 & Dakar & 52.8 & & {$[27]$} \\
\hline 2014 & Dakar & & $43.2 \%$ & Present data \\
\hline
\end{tabular}


Table 6 Evolution of pfmdr1 N86Y mutation in P. falciparum parasites in Senegal

\begin{tabular}{llll}
\hline Year of collection & Site of collection & N86Y & References \\
\hline 2000 & Pikine & $31 \%$ & {$[18]$} \\
2001 & Pikine & $30.6 \%$ & {$[20]$} \\
$2002-2003$ & Pikine & $40 \%$ (about) & {$[19]$} \\
$2005-2009$ & Pikine & $20 \%$ (about) & {$[19]$} \\
2009 & Thiès & $20 \%$ (about) & {$[22]$} \\
$2009-2010$ & Dakar & $17.2 \%$ & {$[24]$} \\
$2010-2011$ & Dakar & 16.1 & {$[25]$} \\
2011 & Thiès & $<5 \%$ & {$[22]$} \\
$2013-2014$ & Dakar & $6.1 \%$ & Present data \\
\hline
\end{tabular}

in recurrent infections after treatment with artemether plus lumefantrine [33-36] or artesunate plus mefloquine [37], which suggests that N86 is a marker of in vivo lumefantrine resistance. In addition, parasites harbouring both the N86 and 184F alleles were less susceptible to lumefantrine and mefloquine in vitro [29]. This profile was detected in $50.5 \%$ of the isolates collected in Dakar.

Conversely, the pfmdr1 $86 \mathrm{Y}$ mutation has been shown to be associated with in vivo amodiaquine resistance during recrudescence after amodiaquine monotherapy [38] or after combination therapy with artesunate-amodiaquine [39]. The odds ratio for amodiaquine therapeutic failure associated with the $86 \mathrm{Y}$ mutation was 5.4 [40]. These results may suggest a low prevalence of $P$. falciparum strains resistant to amodiaquine in Dakar. These data are in contrast with previous studies in Senegal: (i) the $86 \mathrm{Y}$ mutation was significantly associated with increased susceptibility to monodesethylamodiaquine, the active metabolite of amodiaquine, in parasites collected from 2009 to 2011 in Dakar [29]; (ii) the prevalence of isolates with reduced in vitro susceptibility to monodesethylamodiaquine increased significantly from $5.6 \%$ in 2013 to $30.6 \%$ in 2014 with an increase in $\mathrm{IC}_{50}$ values from 9.8 to $25.3 \mathrm{nM}[26,27]$; (iii) the re-increase of $P$. falciparum strains resistant to chloroquine appears to be due to crossresistance between in vitro susceptibility to chloroquine and monodesethylamodiaquine $[23,28]$ and the use of artesunate-amodiaquine in Senegal, which can generate the emergence of parasites resistant to amodiaquine. The increase in amodiaquine $\mathrm{IC}_{50}$ values was already observed in isolates collected in Thiès between 2008 and 2011 [22].

The $p f d h f r 108 \mathrm{~N}$ mutation has been found to be correlated with in vitro and in vivo resistance to pyrimethamine [5, 41]. The risk of therapeutic failure with sulfadoxine-pyrimethamine was greater for patients harbouring the $108 \mathrm{~N}$ mutation (odds ratio of 3.5) during a 28 day follow-up [40]. Additional mutations-51I (odds ratio of 1.7) or 59R (odds ratio of 1.9) -increase the level of in vitro resistance to anti-folate drugs and sulfadoxine-pyrimethamine [40]. The risk of in vivo resistance to sulfadoxine-pyrimethamine increased by 4.3 with the triple mutation (108N, 51I and 59R) [40]. In 2013-2014, the prevalence of the $p f d h f r 108 \mathrm{~N}$ mutation was $87.9 \%$ in malaria patients who were treated at the Hôpital Principal de Dakar. $d$ fhr triple mutants at codons 51I, 59R and $108 \mathrm{~N}$ were associated with high-level pyrimethamine resistance and represented $82.3 \%$ of the isolates. Since 2002 , the prevalence of triple mutants has increased from 50 to $82.3 \%$ in 2013-2014 (Table 7). This increase was observed in different areas of Senegal [3, 42, 43].

The pfdhps 437G mutation has been shown to be correlated with in vitro and in vivo resistance to sulfadoxine [6]. The risk of therapeutic failure with sulfadoxine-pyrimethamine increased by 1.5 and 3.9 with the single mutation A437G and the double mutation A437G and K540E, respectively [40]. In 2013-2014, $47.2 \%$ of the isolates harboured the $437 \mathrm{G}$ mutation in Dakar. This prevalence increased after 2002 and was then stable from 2009 to 2014 with $40-50 \%$ of the isolates harbouring the $437 \mathrm{G}$ mutation in Senegal (Table 8). Several studies from 2006 to 2008 in Senegal showed that the prevalence of pfdhps 437G significantly increased after IPT of infants with sulfadoxinepyrimethamine $[3,44]$. Only two isolates $(2.1 \%)$ carried the double mutation (437G and 540E) that is associated with high-level sulfadoxine resistance. The pfdhps mutation of codon 613 (A613S) (3.2\%) is very rare in Africa.

In Dakar, the prevalence of isolates harbouring the quadruple mutants (dhfr 108N, 51I, 59R and dhps 437G) was stable from 2009 to $2014: 36.5 \%$ in $2009,36.7 \%$ in 2010 and $40.4 \%$ in 2014 [24, 25]. In Thiès, the prevalence of quadruple mutants increased from 20 to $66 \%$ between 2003 and 2011 and then dropped to $44 \%$ in 2013 [43]. In 2010, the quadruple mutants were identified in $79.4 \%$ of the isolates from areas of Senegal where sulfadoxinepyrimethamine plus amodiaquine were administered

Table 7 Evolution of pfdhfr 511, 59R and 108N triple mutation in P. falciparum parasites in Senegal

\begin{tabular}{llll}
\hline $\begin{array}{l}\text { Year of collec- } \\
\text { tion }\end{array}$ & $\begin{array}{l}\text { Site of collec- } \\
\text { tion }\end{array}$ & $\begin{array}{l}\mathbf{5 1 I , 5 9 R , ~ 1 0 8 N} \\
\mathbf{( \% )}\end{array}$ & References \\
\hline 2002 & Dakar & 50 & {$[21]$} \\
2003 & Pikine & 61 & {$[42]$} \\
2003 & Thies & 40 & {$[43]$} \\
2007 & Keur Soce & 67 & {$[3]$} \\
$2009-2010$ & Dakar & 75.3 & {$[24]$} \\
$2010-2011$ & Dakar & 73.6 & {$[25]$} \\
2011 & Thiès & 93 & {$[43]$} \\
$2013-2014$ & Dakar & 82.3 & Present data \\
\hline
\end{tabular}


Table 8 Evolution of pfdhps A437G mutation in P. falciparum parasites in Senegal

\begin{tabular}{llll}
\hline Year of collection & Site of collection & A437G (\%) & References \\
\hline 2002 & Dakar & 20 & {$[21]$} \\
2003 & Pikine & 40 & {$[42]$} \\
$2009-2010$ & Dakar & 40.4 & {$[24]$} \\
$2010-2011$ & Dakar & 47.5 & {$[25]$} \\
$2013-2014$ & Dakar & 47.2 & Present data \\
\hline
\end{tabular}

to children during seasonal malaria chemoprevention versus $67.1 \%$ in areas where they were not treated [45]. In 2014, only one isolate harboured the pfdhps mutations $437 \mathrm{G}$ and $540 \mathrm{E}$ and the pfdhfr mutations $108 \mathrm{~N}, 51 \mathrm{I}$ and 59R; these mutations are associated with high-level sulfadoxine-pyrimethamine resistance. These findings suggest that regular surveillance of molecular markers should be performed in areas where IPT with sulfadoxine-pyrimethamine is used.

In summary, the prevalence of chloroquine resistance continues to increase after a decline due to the official withdrawal of the drug and the introduction of ACT. Furthermore, amodiaquine susceptibility may be decreased as a result of cross-resistance. The frequency of the pfmdr1 mutation N86Y declined while the frequency of the Y184F mutation increased, suggesting that selective pressure is acting on $p f m d r 1$, leading to a high prevalence in these isolates and the lack of specific mutations. The $50.5 \%$ prevalence of the pfmdr1 polymorphisms N86 and $184 \mathrm{~F}$ suggests a decrease in lumefantrine susceptibility. Based on these results, intensive surveillance of ACT partner drugs must be conducted regularly in Senegal.

Furthermore, molecular surveillance in Dakar has demonstrated the emergence of polymorphisms in the K13 propeller domain gene, which is associated with in vitro and in vivo resistance to artemisinin in Asia [46-48]. However, these mutations detected in Dakar and more generally in Africa have not yet been associated with artemisinin resistance.

\section{Abbreviations \\ ACT: artemisinin-based combination therapy; pfcrt: Plasmodium falciparum chloroquine resistance transporter gene; pfmdr1: Plasmodium falciparum multidrug resistance $1 \mathrm{gene}$ pfdhfr: Plasmodium falciparum dihydrofolate reductase gene; pfdhps: Plasmodium falciparum dihydropteroate synthase; IPT: intermittent preventive treatment; WHO: World Health Organization; SNPS: single-nucleotide polymorphisms; DNA: deoxyribonucleic acid.}

\section{Authors' contributions}

$A B, N B$ and MM carried out the molecular genetic studies. BF, KAW, MF, AN, $K K F, P D, B D, Y D$ and BW carried out the diagnostic tests, monitored the patients, collected clinical and epidemiological data. BP conceived of and coordinated the study. AB, MM and BP analysed the data and drafted the manuscript. All authors read and approved the final manuscript.

\begin{abstract}
Author details
${ }^{1}$ Unité de Parasitologie et d'Entomologie, Département des Maladies Infectieuses, Institut de Recherche Biomédicale des Armées, Brétigny Sur Orge, France. ${ }^{2}$ Laboratoire d'étude de la chimiosensibilité du paludisme, Fédération des Laboratoires, Hôpital Principal de Dakar, Dakar, Senegal. ${ }^{3}$ Equipe Résidente de Recherche en Infectiologie Tropicale, Institut de Recherche Biomédicale des Armées, Hôpital d'Instruction des Armées, Marseille, France. ${ }^{4}$ Unité de Recherche sur les Maladies Infectieuses et Tropicales Emergentes, UM 63, CNRS 7278, IRD 198, Inserm 1095, Aix Marseille Université, Marseille, France. ${ }^{5}$ Centre National de Référence du Paludisme, Marseille, France. ${ }^{6}$ Service des Urgences, Hôpital Principal de Dakar, Dakar, Senegal. ${ }^{7}$ Service de Réanimation Médicale, Hôpital Principal de Dakar, Dakar, Senegal. ${ }^{8}$ Service de Pédiatrie, Hôpital Principal de Dakar, Dakar, Senegal. ${ }^{9}$ Service de Pathologie Infectieuse, Hôpital Principal de Dakar, Dakar, Senegal. ${ }^{10}$ Maternité Hôpital Principal de Dakar, Dakar, Senegal. ${ }^{11}$ Chefferie, Hôpital Principal de Dakar, Dakar, Senegal.
\end{abstract}

\section{Acknowledgements}

The authors thank the patients and the staff of the Hôpital Principal de Dakar. The authors thank Ndeye Fatou Diop and Maurice Gomis from the Hôpital

Principal de Dakar for technical support.

\section{Competing interests}

The authors declare that they have no competing interests.

\section{Availability of data and material}

We didn't wish to share our data. There is no recommended repository for the kind of data showed in this publication. All the data have not been yet valued.

\section{Ethics approval and consent to participate}

All the patients or their parents/guardians provided their verbal consent before blood collection. Bio-banking and secondary use for scientific purposes of human clinical samples used for malaria diagnostic are possible as long as the corresponding patients are informed and have not indicated any objections. This requirement was fulfilled here since oral information is given to every patient and no immediate or delayed patient opposition was reported to the hospital clinicians.The ethical committee of the Hôpital Principal de Dakar approved the study.

\section{Funding}

This study was supported by the Schéma directeur Paludisme, Etat Major des Armées Françaises (Grant LR 607a), by the Délégation Générale pour I'Armement (Grant PDH-2-NRBC-4-B1-402) and by the Ministère des Affaires Etrangères.

Received: 19 March 2016 Accepted: 8 June 2016

Published online: 07 July 2016

\section{References}

1. Cissé B, Sokhna C, Boulanger D, Milet J, Ba EH, Richardson K, et al. Seasonal intermittent preventive treatment with artesunate and sulfadoxine-pyrimethamine for prevention of malaria in Senegalese children: a randomized, placebo-controlled, double-blind trial. Lancet. 2006;367:659-67.

2. Sokhna C, Cissé B, Ba EH, Milligan P, Hallett R, Sutherland C, et al. A trial of the efficacy, safety and impact on drug resistance of four drug regimens for seasonal intermittent preventive treatment for malaria in Senegalese children. PLoS One. 2008;3:1471

3. Cissé B, Cairns M, Faye E, NDiaye O, Faye B, Cames C, et al. Randomized trial of piperaquine with sulfadoxine-pyrimethamine or dihydroartemisinin for malaria intermittent preventive treatment in children. PLoS One. 2009:4:7164.

4. Fidock DA, Nomura T, Talley AK, Cooper RA, Dzekunov SM, Ferdig MT, et al. Mutations in the P. falciparum digestive vacuole transmembrane protein PfCRT and evidence for their role in chloroquine resistance. Mol Cell. 2000;6:861-71.

5. Price RN, Uhlemann AC, Brockman A, McReady R, Ashley E, Phaipun L, et al. Mefloquine resistance in Plasmodium falciparum and increased pfmdr1 gene copy number. Lancet. 2004;364:438-47. 
6. Henry M, Alibert S, Orlandi-Pradines E, Bogreau H, Fusai T, Rogier C, et al. Chloroquine resistance reversal agents as promising antimalarial drugs. Curr Drug Targets. 2006;7:935-48.

7. Henry M, Alibert S, Rogier C, Barbe J, Pradines B. Inhibition of efflux of quinolines as new therapeutic strategy in malaria. Curr Top Med Chem. 2008;8:563-78.

8. Zolg JW, Plitt JR, Chen GX, Palmer S. Point mutations in the dihydrofolate reductase-thymidylate synthase gene as the molecular basis for pyrimethamine resistance in Plasmodium falciparum. Mol Biochem Parasitol. 1989;36:253-62.

9. Wang P, Read M, Sims PF, Hyde JE. Sulfadoxine resistance in the human malaria parasite Plasmodium falciparum is determined by mutations in dihydropteroate synthetase and an additional factor associated with folate utilization. Mol Microbiol. 1997;23:979-86.

10. Tinto $H$, Ouédraogo JB, Erhart $A$, van Overmeir C, Dujardin JC, van Marck $\mathrm{E}$, et al. Relationship between the Pfcrt T76 and the Pfmdr-1 Y86 mutations in Plasmodium falciparum and in vitro/in vivo chloroquine resistance in Burkina Faso, West Africa. Infect Genet Evol. 2003;3:287-92.

11. Basco LK, Ringwald P. Molecular epidemiology of malaria in Cameroon.X. Evaluation of Pfmdr 1 mutations as genetic markers for resistance to amino alcohols and artemisinin derivatives. Am J Trop Med Hyg. 2002:66:667-71

12. Parola P, Pradines B, Simon F, Carlotti MP, Minodier P, Ranjeva MP, et al. Antimalarial drug susceptibility and point mutations associated with resistance in 248 Plasmodium falciparum isolates imported from Comoros to Marseille. Am J Trop Med Hyg. 2007;77:431-7.

13. Programme national de lutte contre le paludisme. Bulletin épidémiologique annuel du paludisme au Sénégal. 2015. (www.pnlp.sn/ telechargements/Rapports/BULLETIN-EPIDEMIOLOGIQUE-ANNUEL2014-DU-PALUDISME-AU-SENEGAL.pdf).

14. Djimdé A, Doumbo OK, Cortese JF, Kayentao K, Doumbo S, DiourtéY, et al. A molecular marker for chloroquine-resistant falciparum malaria. N Engl J Med. 2001;344:257-63.

15. Pradines B, Tall A, Parzy D, Spiegel A, Fusai T, Hienne R, et al. In vitro activity of pyronaridine and amodiaquine against African isolates (Senegal) of Plasmodium falciparum in comparison with standard antimalarial agents. J Antimicrob Chemother. 1998:42:333-9.

16. Pradines B, Tall A, Ramiandrasoa F, Spiegel A, Sokhna C, Fusai T, et al. In vitro activity of iron-binding compounds against Senegalese isolates of Plasmodium falciparum. J Antimicrob Chemother. 2006:57:1093-9.

17. Pradines B, Tall A, Rogier C, Spiegel A, Mosnier J, Marrama L, et al. In vitro activities of ferrochloroquine against 55 Senegalese isolates of Plasmodium falciparum in comparison with those of standard antimalarial drugs. Trop Med Int Health. 2002;7:265-70.

18. Thomas SM, Ndir O, Dieng T, Mboup S, Wypij D, Maguire JH, et al. In vitro chloroquine susceptibility and PCR analysis of pfcrt and pfmdr 1 polymorphisms in Plasmodium falciparum isolates from Senegal. Am J Trop Med Hyg. 2002;66:474-80.

19. Ly O, Gueye PE, Deme AB, Dieng T, Badiane AS, Ahouidi AD, et al. Evolution of the pfcrt T76 and pfmdr 1 Y86 markers and chloroquine susceptibility 8 years after cessation of chloroquine use in Pikine, Senegal. Parasitol Res. 2012;111:1541-6.

20. Sarr O, Myrick A, Daily J, Diop BM, Dieng T, Ndir O, et al. In vivo and in vitro analysis of chloroquine resistance in Plasmodium falciparum isolates from Senegal. Parasitol Res. 2005;97:136-40.

21. Henry M, Diallo I, Bordes J, Ka S, Pradines B, Diatta B, et al. Urban malaria in Dakar, Senegal: chemosusceptibility and genetic diversity of Plasmodium falciparum isolates. Am J Trop Med Hyg. 2006;75:146-51.

22. Van Tyne D, Dieye B, Valim C, Daniels RF, Diogoye Sène P, Lukens AK, et al. Changes in drug sensitivity and anti-malarial drug resistance mutations over time among Plasmodium falciparum parasites in Senegal. Malar J. 2013:12:441.

23. Fall B, Diawara S, Sow K, Baret E, Diatta B, Fall KB, et al. Ex vivo susceptibility of Plasmodium isolates from Dakar, Senegal, to seven standard antimalarial drugs. Malar J. 2011;10:310.

24. Wurtz N, Fall B, Pascual A, Diawara S, Sow K, Baret E, et al. Prevalence of molecular markers of Plasmodium falciparum drug resistance in Dakar, Senegal. Malar J. 2012;11:197.

25. Fall B, Pascual A, Sarr FD, Wurtz N, Richard V, Baret E, et al. Plasmodium falciparum susceptibility to anti-malarial drugs in Dakar, Senegal, in
2010: an ex vivo and drug resistance molecular markers study. Malar J. 2013;12:107.

26. Fall B, Camara C, Fall M, Nakoulima A, Dionne P, Diatta B, et al. Plasmodium falciparum susceptibility to standard and potential anti-malarial drugs in Dakar, Senegal, during the 2013-2014 malaria season. Malar J. 2015;14:60.

27. Fall B, Madamet M, Camara C, Amalvict R, Fall M, Nakoulima A, et al. Emergence of Plasmodium falciparum in vitro resistance to monodesethylamodiaquine in Dakar, Senegal in 2014. Emerg Infect Dis. 2016;22:841-5.

28. Pradines B, Mabika Mamfoumbi M, Parzy D, Owono Medang M, Lebeau C, Mourou Mbina JR, et al. In vitro susceptibility of African ioslates of Plasmodium falciparum from Gabon to pyronaridine. Am J Trop Med Hyg. 1999;60:105-8

29. Wurtz N, Fall B, Pascual A, Fall M, Baret E, Camara C, et al. Role of Pfmdr in in vitro susceptibility to chloroquine, quinine, monodesethylamodiaquine, mefloquine, lumefantrine and dihydroartemisinin. Antimicrob Agents Chemother. 2014;58:7032-40.

30. Mungthin M, Khositnithikul R, Sitthichot N, Suwandittakul N, Wattanaveeradej $\mathrm{V}$, Ward SA, et al. Association between the pfmdr 1 gene and in vitro artemether and lumefantrine sensitivity in Thai isolates of Plasmodium falciparum. Am J Trop Med Hyg. 2010;83:1005-9.

31. Mwai L, Kiara SM, Abdirahman A, Pole L, Rippert A, Diriye A, et al. In vitro activities of piperaquine, lumefantrine, and dihydroartemisinin in Kenyan Plasmodium falciparum isolates and polymorphisms in pfcrt and pfmdr 1. Antimicrob Agents Chemother. 2009;53:5069-73.

32. Dahlström S, Aubouy A, Maïga-Ascofaré O, Faucher JF, Wakpo A, Ezinmègnon $\mathrm{S}$, et al. Plasmodium falciparum polymorphism associated with ex vivo drug susceptibility and clinical effectiveness of artemisininbased combination therapies in Benin. Antimicrob Agents Chemother. 2014:58:1-10

33. Sisowath C, Stromberg J, Martensson A, Msellem M, Obondo C, Björkman A, Gil JP. In vivo selection of Plasmodium falciparum pfmdr1 86N coding alleles by artemether-lumefantrine (Coartem). J Infect Dis. 2005;2005(191):1014-7.

34. Sisowath C, Ferreira PE, Bustamante LY, Dahlström S, Martensson A, Bjorkman A, et al. The role of pfmdr 1 in Plasmodium falciparum tolerance to artemether-lumefantrine in Africa. Trop Med Int Health. 2007;12:736-42.

35. Martensson A, Stromberg J, Sosowath C, Msellem MI, Gil JP, Montgomery $S M$, et al. Efficacy of artesunate plus amodiaquine versus that of artemether-lumefantrine for the treatment of uncomplicated childhood Plasmodium falciparum malaria in Zanzibar, Tanzania. Clin Infect Dis. 2005:41:1079-86.

36. Dokomajilar C, Nsobya SL, Greenhouse B, Rosenthal PJ, Dorsey G. Selection of Plasmodium falciparum pfmdr1 alleles following therapy with artemether-lumefantrine in an area of Uganda where malaria is highly endemic. Antimicrob Agents Chemother. 2006;50:1893-5.

37. Price RN, Uhlemann AC, Brockman A, McGready R, Ashley E, Phaipun $L$, et al. Mefloquine resistance in Plasmodium falciparum and increased pfmdr1 gene copy number. Lancet. 2004;364:438-47.

38. Holmgren G, Gil JP, Ferreira PM, Veiga MI, Obonyo CO, Bjorkman A. Amodiaquine resistant Plasmodium falciparum malaria in vivo is associated with selection of pfcrt 76T and pfmdr1 86Y. Infect Gen Evol. 2006;6:309-14.

39. Nsobya SL, Dokomajilar C, Joloba M, Dorsey G, Rosenthal PJ. Resistancemediating Plasmodium falciparum pfcrt and pfmdr 1 alleles after treatment with artesunate-amodiaquine in Uganda. Antimicrob Agents Chemother. 2007;51:3023-5.

40. Picot S, Olliaro P, de Monbrison F, Bienvenu AL, Price RN, Ringwald P. A systematic review and meta-analysis of evidence for correlation between molecular markers of parasite resistance and treatment outcome in falciparum malaria. Malar J. 2009;8:89.

41. Sibley CH, Hyde JE, Sims PF, Plowe CV, Kublin JG, Mberu EK, et al. Pyrimethamine-sulfadoxine resistance in Plasmodium falciparum: what next? Trends Parasitol. 2001;17:582-8.

42. Ndiaye D, Dailly JP, Sarr O, Ndir O, Gaye O, Mboup S, et al. Mutations in Plasmodium falciparum dihydrofolate reductase and dihydropteroate synthase genes in Senegal. Trop Med Int Health. 2005;10:1176-9.

43. Ndiaye D, Dieye B, van Tyne D, Daniels R, Bei AK, Mbaye A, et al. Polymorphism in $\mathrm{dhfr} / \mathrm{dhps}$ genes, parasite density and ex vivo response to pyrimethamine in Plasmodium falciparum malaria parasites in Thies, Senegal. Int J Parasitol Drugs Drug Resist. 2013;3:135-42. 
44. Faye B, Ndiaye M, Ndiaye JL, Annie A, Tine RC, Collé Lo A, et al. Prevalence of molecular markers of Plasmodium falciparum resistance to sulfadoxine-pyrimethamine during the intermittent preventive treatment in infants coupled with expanded program immunization in Senegal. Parasitol Res. 2011;109:133-8.

45. Lo AC, Faye B, Ba EH, Cisse B, Tine R, Abiola A, et al. Prevalence of molecular markers of drug resistance in an area of seasonal malaria chemoprevention in children in Senegal. Malar J. 2013;12:137.

46. Boussaroque A, Fall B, Madamet M, Camara C, Benoit N, Fall M, et al. Emergence of mutations in the K13 propeller domain gene of Plasmodium falciparum isolates from Dakar, in 2013-2014. Antimicrob Agents Chemother. 2016;60:624-7.

47. Ariey F, Witkowsky B, Amaratunga C, Beghain J, Langlois AC, Khim N, et al. A molecular marker of artemisinin-resistant Plasmodium falciparum malaria. Nature. 2014;505:50-5.

48. Ashley EA, Dhorda M, Fairhurst RM, Amaratunga C, Lim P, Suon S, et al. Spread of artemisinin resistance in Plasmodium falciparum malaria. N Engl J Med. 2015;371:411-23.

\section{Submit your next manuscript to BioMed Central and we will help you at every step:}

- We accept pre-submission inquiries

- Our selector tool helps you to find the most relevant journal

- We provide round the clock customer support

- Convenient online submission

- Thorough peer review

- Inclusion in PubMed and all major indexing services

- Maximum visibility for your research

Submit your manuscript at

www.biomedcentral com/submit 